\title{
DC / DC converters as DC circuit-breakers in HVDC networks operation.
}

\author{
M. Jiménez Carrizosa , J. Cortés , A. Benchaib , P. Alou , G. Damm \\ J. A. Cobos and Françoise Lamnabhi-Lagarrigue
}

\section{Acknowledgments}

This work is supported by WINPOWER project (ANR-10-SEGI-016).

\section{Keywords}

$<<$ DC/DC bidirectional converters $>>,\langle<$ DAB $\rangle>,<<$ nonlinear control $>>,<<$ VSC-HVDC $>>$, $<<$ DC circuit-breaker $>>$

\begin{abstract}
This paper presents the modeling and control of a DC/DC bidirectional converter suitable for medium voltage and power applications in Multi-Terminals HVDC (MT-HVDC) grids. Moreover its use as DC circuit-breaker is described. This is a new concept, against the contemporary studies of DC breakers, which could help for the implementation of MT-HVDC networks. The proposed multilevel topology is based on Dual Active Bridge (DAB). The overall control of the DC/DC converter is achieved by using a nonlinear control based in Lyapunov theory.
\end{abstract}

\section{Introduction}

With the advent of renewable energies, global energy scenario has changed and does not depend anymore only on nuclear and fossil energies. These classical energies sources produce serious environmental problems: the increased of pollution and greenhouse effect due to the high amount of $\mathrm{CO}_{2}$, in the case of fossils energies, or the highly contaminating nuclear wastes. Moreover these non-renewable energies are limited, thus their prices are likely to continue increasing. This context provides new challenges to find a new energy outline with higher performances, and where renewable sources will gradually replace nonrenewable sources. Due to their variability and intermittent nature, the integration of renewable energies is not an easy task with the current available technology, since the current devices are not designed to work with such variability.

Historically, electric power transmission has been carried out in $\mathrm{AC}$ three phase systems, mainly due to power transformers which are capable to change voltages. However, AC transmission systems need reactive power compensation which, in some situations, can be very delicate. As opposed, in DC systems this point does not exit. Some authors assert that for onshore distances longer than $500 \mathrm{~km}$ is preferable the use HVDC systems. For offshore lines, this break-even distance falls to only $50 \mathrm{~km} \mathrm{[1],} \mathrm{[2]} \mathrm{and}$ [3]. This fact, together with the development of electronic devices as DC-DC converters for high voltage explain that, nowadays, researches are focused in MT-HVDC networks to integrate renewables, as for example, offshore wind farms.

Until development of VSC (voltage source converters), HVDC systems used CSC (current source converters) to carry out the inversion and rectification. VSC converters use IGBTs and CSC use thyristors. VSC-HVDC systems present many advantages compared with CSC-HVDC systems. Some of them are are: simultaneous control of active and reactive power, they create any phase angle or voltage magnitude (within certains limits), improvement of AC voltage waveform, amelioration of Total Harmonic Distortion (THD), AC filters size minimization and black start [4]. Also CSC systems need communication between converters and in VSC systems this is not required [4]. 
In this paper we will employ VSC-HVDC systems with different DC voltage values, so it is necessary to use bidirectional DC/DC converters. The application and control of these type of converters are stressed in several publications as [5, 6]. The DC/ DC converters could be also employed like a tool to operate the HVDC, as explained in [7]. Another interesting fact is that DC/DC converters could be also employed as DC circuit-breakers. This property is very important in the further development and establishment of MT-HVDC networks, because until now there is no device which can assure safety of an electric circuit from damage caused by overload or short circuit, as it exits in AC systems [8], [9]. For this reason, and because the proposed DC-DC converter includes an AC stage, there are instants in which the current passes through zero. This fact can be used to open the switches when a short circuit occurs in the network, and consequently the converter itself acts as a DC circuit breaker. The proposed converters would be located according to figure 1 .

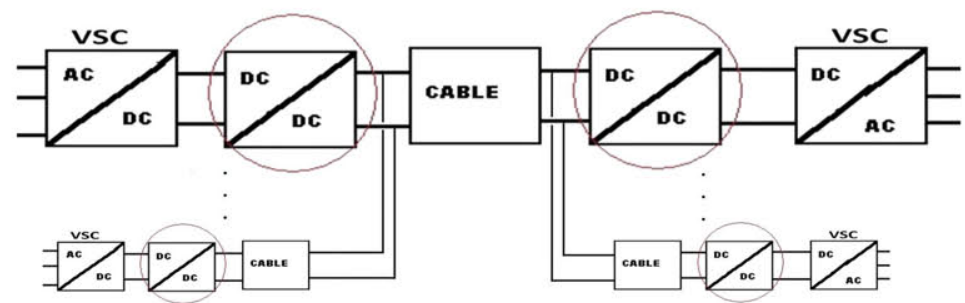

Figure 1: Scheme general.

The paper is outlined as follows: Section I presents the introduction and the background information on the study. Section II presents the modeling and control of a DAB converter. The proposed control is a robust nonlinear control based on Lyapunov theory. Section III presents the robustness of the controller. Section IV shows the use of the converter as a tool to control the power flows. In Section $\mathbf{V}$ the use of the converter as a DC circuit-breaker is explained. Finally in Section VI the conclusions are outlined.

\section{DC-DC converter controller}

With the development of power electronics and semiconductors devices (such as IGBTs), it is possible to use bidirectional DC-DC converters for high voltage and high power applications. In [7] the modeling and control of a DC/DC bidirectional converter with a special interest in wind-power applications is proposed. The suggested topology converter is based on Dual Active Bridge (DAB) (see figure 2). The overall control of the DC/DC converter is achieved by using a nonlinear control based in Lyapunov theory.

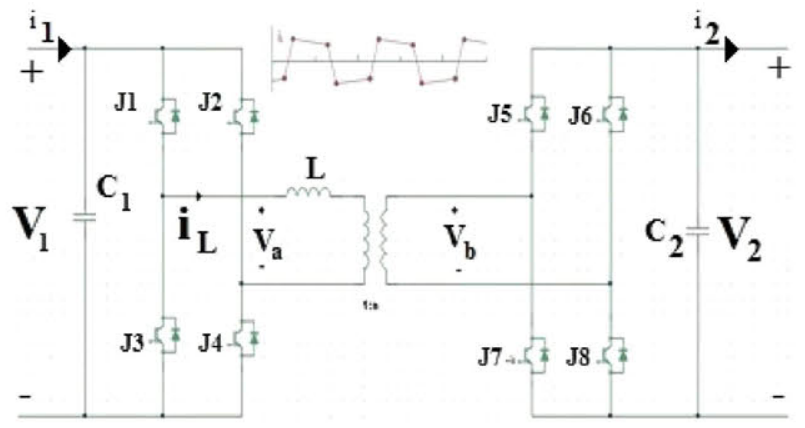

Figure 2: Dual Active Bridge.

In the intermediate stage (AC) a medium frequency transformer is used $[5,6]$. It provides insulation and the step up/down of the different voltage levels. This transformer is based on a single magnetic core with windings in both legs of the core. Using this type of transformer the ratio weight / volume can be improve. It works at frequencies around $1-20 \mathrm{kHz}$ [5]. For this type of converter SiC-JFETs can be used $[10,11,12,13]$, but is not the object of this paper to study in depth this matter.

In order to design the nonlinear control based on Lyapunov theory a differential equation that models the real system is required. The control is performed on the mean value of current $\left\langle i_{1}\right\rangle$, so all calculations based on this will be indicated with respect to the current $i_{1}$. In [7] it was demonstrated that the differential equation which governs the system is:

$$
\frac{d}{d t}<i_{1}>(t)=-\frac{R}{L} \cdot\left\langle i_{1}>(t)+\frac{T \cdot R}{L^{2}} \cdot D \cdot(1-2|D|) \frac{V_{2}}{n}\right.
$$


where $L$ is the inductance value, $R$ is the total resistance of the system, $D$ is the phase shift ratio between voltages applied to inductance $(-0.5 \leq D \leq 0.5), n$ is the transformer ratio, $T$ is period of each cycle and $V_{2}$ is the voltage in the right side.

\subsubsection{Nonlinear control design for DAB system}

The proposed control law will be based on Lyapunov theory $[14,15]$. It has been chosen because our system is nonlinear, and the stability is assured in all domain, and not only in a region if we had linearized the system. Also, the Lyapunov theory is a powerful tool for unbalance systems. Development of the calculations for the control law will be shown in full version. Consider the dynamic model represented in equation 1. Our objective is to track the reference of the average current $\left\langle i_{1}\right\rangle_{r e f}$. Consider the following Lyapunov energy function shown in 2, which represents the required energy for the current to converge to its reference.

$$
F=\frac{1}{2}\left(<i_{1}>-<i_{1}>_{r e f}\right)^{2}
$$

Its derivate time is:

$$
\frac{d}{d t} F=E \cdot\left(-\frac{R}{L}<i_{1}>(t)+\frac{T R}{L^{2}} \cdot D \cdot(1-2|D|) \frac{V_{2}}{n}-\frac{d}{d t}<i_{1}>_{r e f}\right)
$$

where $e=\left(\left\langle i_{1}\right\rangle-\left\langle i_{1}\right\rangle_{r e f}\right)$ is the tracking error. In order to achieve desired tracking as well as control stability, it is sufficient to force the time derivative of the Lyapunov function to be negative.

$$
\begin{gathered}
-\frac{R}{L}<i_{1}>(t)+\frac{T R}{L^{2}} \cdot D \cdot(1-2|D|) \frac{V_{1}}{n}-\frac{d}{d t}<i_{1}>_{r e f}= \\
=-\alpha \cdot e-\beta \cdot \operatorname{sign}(e)
\end{gathered}
$$

with the positive tuning gain parameters $\alpha>0, \beta>0$. As it is well known in the sliding mode control theory, the sign function is added to improve the robustness properties of the proposed control law. Thereafter, the time derivative of the Lyapunov function becomes:

$$
\frac{d}{d t} F=-\alpha \cdot e^{2}-\beta \cdot \operatorname{sign}(e) \cdot E \leq 0
$$

Equation 5 satisfies the stability condition, so the following relation holds from equation 4:

$$
D(1-2|D|)=K
$$

where

$$
K=\frac{n \cdot L^{2}}{R T V_{\text {out }}}\left[-\alpha e-\beta \operatorname{sign}(e)+\frac{d}{d t}<i_{1}>_{r e f}+\frac{R}{L}<i_{1}>\right]
$$

Developing equation 6 , we obtain the general solution for the two cases ( $D$ positive or negative) leads to the control law which is able to track the reference and to ensure system stability. The general solution for the two cases leads to the control law is:

$$
D=\frac{1-\sqrt{1-8 K}}{4} \cdot S_{1}+\frac{-1+\sqrt{1+8 K}}{4} \cdot S_{2}
$$

where $S_{1}$ has value 1 if the condition $K>0$ is true and 0 otherwise. The same applies for $S_{2}$ with the condition $K<0$.

However this control is not enough for a situation like a short circuit. It needs measures of the current all the time, or at least with a frequency of measurement similar to the switching frequency. The behavior of this overall control is explained as follows, in normal operation the DC/DC converter is governed by the control explained above, and if a short-circuit occurs then the control changes to emergency mode, and it sends the signals to the semiconductors to open. The semiconductors will open just when the current passes by zero (or close to it).

The time between when the short-circuit occurs and when it is detected is crucial in this task, and actually is in the order of $m s$ [16],[8] and [9], which represents some cycles in the DC/DC converter switching frequency (between 1-20 kHz [5]). Obviously, if we increase the switching frequency we can obtain better behaviors from the point of view of breaker. 
Table I: Robustnesses simulation values.

\begin{tabular}{|c|c|c|}
\hline $\mathrm{n}$ & Transformer ratio & $100 / 11$ \\
\hline$R_{\text {total }}$ & Total resistance & $0.01 \Omega$ \\
\hline$V_{\text {in }}$ & Nominal input voltage & $1000 \mathrm{~V}$ \\
\hline$V_{\text {on }}$ & Nominal output voltage & $12000 \mathrm{~V}$ \\
\hline $\mathrm{L}$ & Inductance & $6.875 \cdot 10^{-5} \mathrm{H}$ \\
\hline $\mathrm{T}$ & Period & $1 / 2000 \mathrm{~s}$ \\
\hline
\end{tabular}

\section{Robustness}

In this section we explore the robustness of the control. This is a very meaningful aspect because all systems are subject to the effects of disturbances and uncertainties. For these reasons, it is important to analyze our controller submit to disturbances.

\subsection{Robustnesses simulations}

With this objective, a singular cell of DAB is tested. Perturbations are included in the simulations for the purpose of verifying our control. These disturbances will be the voltages in each side of the system, which we have considered constant when the controller was developed. A $20 \%$ of difference with respect to the nominal value is included in simulations, remember that in HVDC systems the maximum deviation from the nominal value are usually not greater than $10 \%$ [17]. To simulate the perturbations, random signals with sample time equals to $1 \mathrm{~ms}$ has been considered in both sides. Simulations have been carried out in SIMULINK-MATLAB environment. Data from this system is shown in table I.

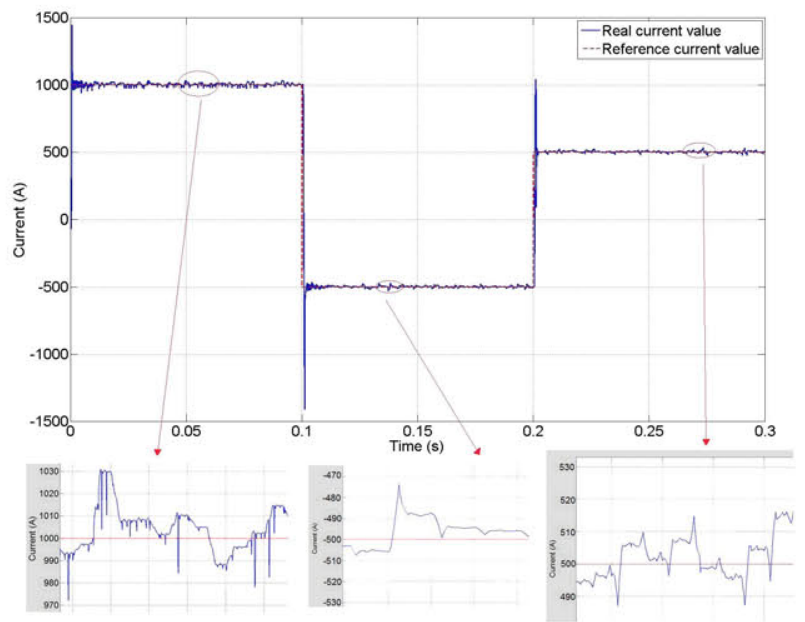

Figure 3: Current average value in left side of single DAB cell under unbalance situation.

In view of figure 3 , we can observe how despite there is a variation grater than $20 \%$ in the capacitor voltages, the designed control allows that the current follows its reference, and also one can remark that the real current does not exceed $10 \%$ of reference. Considering the simulations, we can affirm that our control is robust to disturbances, such as they happen in reality.

\section{Power flow control}

As was shown in [7], it is possible to control the power flow between terminals, simply providing the desired reference to the current. The intuitive idea is that as at each side of the converter there is an energy storage element, if they are large enough we can remove or introduce energy with the appropriate current reference. Also, if the capacitors are large enough, their voltages will not change abruptly, which supports us the idea that voltages remain more or less constant in both sides of the converter. It should be noted that in figure 4 we have included two DC/DC converters in each line in order to increase the safety of the line, because they may be used as DC circuit breakers and also because they are needed in order to increase the voltage values to decrease the transmission losses. Although obviously, they would raise the installation total cost, but that is a debate which is not addressed in this paper. 
Figure 4 shows a multi-terminal network in which we apply our control to each converter in order to obtain the desired power flows. The proposed system comprises a generator node (wind farm), a consumer node $(B)$ and a node where there is a storage device $(C)$, so in it, we can absorb or supply energy at any instant as appropriate. At this point, it should be mentioned that in each line there are two DC/DC converters, by the reasons explained above, and one of them is controlled as current source and the other as voltage source, that means, the converter which is controlled as current source is responsible to provide the reference to the power (by means to appropriate current reference) and the other is responsible to keep the voltage of the line (it works as voltage source). In figure 4 we have chosen that the even ones are working in current source mode and the odd ones in voltage source mode.

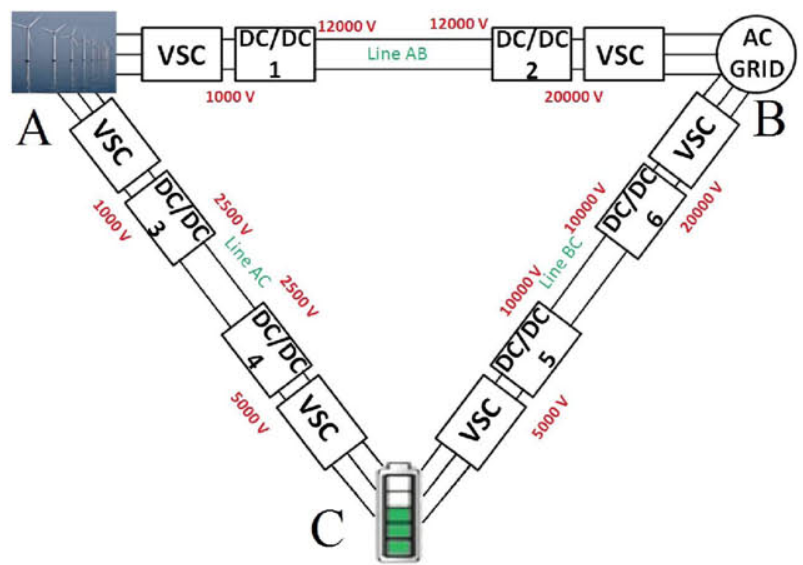

Figure 4: Multi-terminal HVDC system.

It must point out that as switching converter frequencies are high, then the control signals will also be fast, and as both are much faster than the dynamics of the wind farm, the storage device or the consumer node, then the power can be adjusted according to the necessities of the system all the time.

\subsection{Simulations section IV}

Data from this system are shown in table II. The model of transmission cables have been emulated using a $\pi$ equivalent. An inductance, a resistance and a capacitor have been considered to emulate each HVDC cable $[18,19]$.

In figure 5 we can distinguish four different states. The first is between $0<t<0.5 \mathrm{~s}$, where the wind farm supplies $1 \mathrm{MW}$ by means of the corresponding current reference. The node $\mathrm{C}$ absorbed $0.9 \mathrm{MW}$ and the storage device absorbs the excess, about $0.1 \mathrm{MW}$ (slightly less due to losses in the system). The second state is between $0.5<t<1 \mathrm{~s}$, the production of the wind changes to $0.5 \mathrm{MW}$, in the same instant the power demand by the load goes to $0.45 \mathrm{MW}$, and consequently the storage passes to absorb 0.05 MW. The third interval is between $1<t<1.5 \mathrm{~s}$, at this moment there is no wind available, and the load remains at $0.45 \mathrm{MW}$, so the set-point reference to the storage will be to supply $0.45 \mathrm{MW}$ (plus the losses). In the last interval $1.5<t<2 \mathrm{~s}$ the wind begins to grow slowly in steps, while the load begins to demand more power. In these simulations we have assumed that all references come from a higher level controller, which is not studied in this paper.

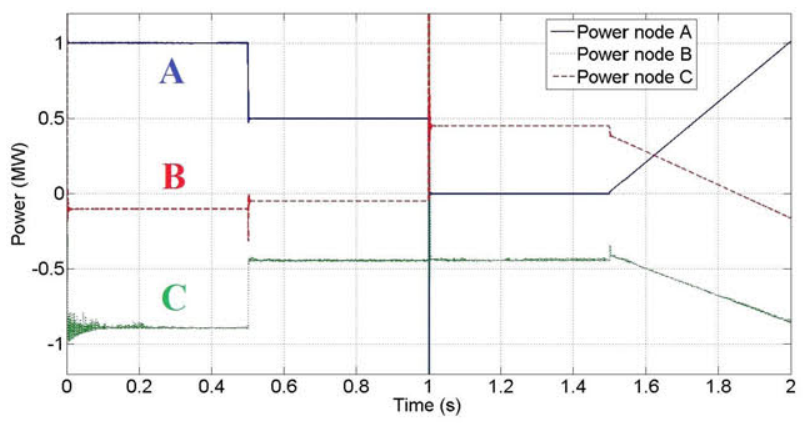

Figure 5: Input power in each node.

The errors between the references and the real values of the current are always smaller than $1 \%$ in all intervals. 
Table II: Three nodes MT-VSC HVDC grid. Simulation values.

\begin{tabular}{|c|c|c|}
\hline$V_{A}$ & Nominal voltage node A & $1000 \mathrm{~V}$ \\
\hline$V_{B}$ & Nominal voltage node B & $20000 \mathrm{~V}$ \\
\hline$V_{C}$ & Nominal voltage node C & $5000 \mathrm{~V}$ \\
\hline$V_{\text {line }-A B}$ & Nominal voltage line AB & $12000 \mathrm{~V}$ \\
\hline$V_{\text {line }-A C}$ & Nominal voltage line AC & $2500 \mathrm{~V}$ \\
\hline$V_{\text {line }-B C}$ & Nominal voltage line BC & $10000 \mathrm{~V}$ \\
\hline$R_{\text {cable }}$ & Cable resistance & $0.0121 \Omega / \mathrm{km}$ \\
\hline$L_{\text {cable }}$ & Cable inductance & $0.121 \mathrm{H} / \mathrm{km}$ \\
\hline$C_{\text {cable }}$ & Cable capacitance & $1 e^{-} 6 \mathrm{~F} / \mathrm{km}$ \\
\hline$l_{\text {line }-A B}$ & Length line AB & $120 \mathrm{~km}$ \\
\hline$l_{\text {line }-A C}$ & Length line AC & $250 \mathrm{~km}$ \\
\hline$l_{\text {line }-B C}$ & Length line BC & $100 \mathrm{~km}$ \\
\hline$R_{\text {total }}$ & Total resistance in each converter & $0.01 \Omega$ \\
\hline$f_{S}$ & Switching frequency & $2000 \mathrm{~Hz}$ \\
\hline \hline & Transformer ratio & $\mathrm{L}$ \\
\hline DC/DC 1 & $10 / 110$ & $6.875 \cdot 10^{-5} \mathrm{H}$ \\
\hline DC/DC 2 & $20 / 11$ & $0.75 \cdot 10^{-3} \mathrm{H}$ \\
\hline DC/DC 3 & $10 / 26$ & $6.875 \cdot 10^{-5} \mathrm{H}$ \\
\hline DC/DC 4 & $50 / 28$ & $3.9 \cdot 10^{-4} \mathrm{H}$ \\
\hline DC/DC 5 & $5 / 11$ & $0.1563 \cdot 10^{-3} \mathrm{H}$ \\
\hline DC/DC 6 & $21 / 10$ & $6.3 \cdot 10^{-3} \mathrm{H}$ \\
\hline
\end{tabular}

\section{DC circuit breaker}

As already discussed above, the DC circuit breaker is a capital device for the future development of MTHVDC networks. DC lines have long been used to transmit power, in particular from large hydroelectric dams to cities, but only in back to back mode. Because it was not safe to connect more than two DC lines into a large-scale grid, research efforts are currently focused on the development of these devices in order to implement MT-HVDC systems.

What is proposed in this section is a new concept, which try to take advantage of the DC / DC converter, employing the internal alternative state of the inductance current in it and the zero crossing of this current. In addition, this property will be used together with its standard application as device to increase/decrease voltage levels. This structure presents some advantages with respect to current DC circuit breakers, which cut off the current with non zero values. The main benefit is to reduce the electric arc, and make safer the cut off of the current. An important property is that the DC circuit breaker has to be selective, and must completely isolate the fault, thus it is crucial to have real measures of the current all the time.

\subsection{Simulations for the whole system.}

We use the same model from section 4, and we simulate a short circuit near the node B in the HVDC, as shown in figure 6. Data from this system are shown in table II.

In figure $7 \mathrm{a}$ it is shown the behavior of the current in the DC/DC converter 2 , the closest to the short circuit, when DC circuit breaker is not inserted. We can remark that when the short-circuit occurs (at $t=0.2 \mathrm{~s}$ ) the current suddenly grows and the short circuit is spread to all parts of the system, which could produce irreparable damages.

However, if we use the DC/DC converter as DC circuit breaker, we obtain the curve shown in figure 7b. We can observe in it that once the short-circuit happens, there is a time $\tau_{1}$ while the short-circuit is not detected and the current increases, this $\tau_{1}$ is in the order of $5 \mathrm{~ms} \mathrm{[16],[8]} \mathrm{and} \mathrm{[9].} \mathrm{Once} \mathrm{the} \mathrm{short-circuit}$ is detected, we observe a time, $\tau_{2}$, which we can define as the time elapsed since the fault is detected and the current through the inductance is zero, instant in which the switches are opened. The same procedure is carried out in DC/DC converter 1 (at the other side of the line $A B$ ), and this is how we have isolated the fault in this line.

Figure 8 shows how the current though the converters $6,5,4$ and 3 . We observe as only in converter 6 the current has a little change in its behavior. This is because the transformers and the VSC converters have been absorbed the short circuit. 


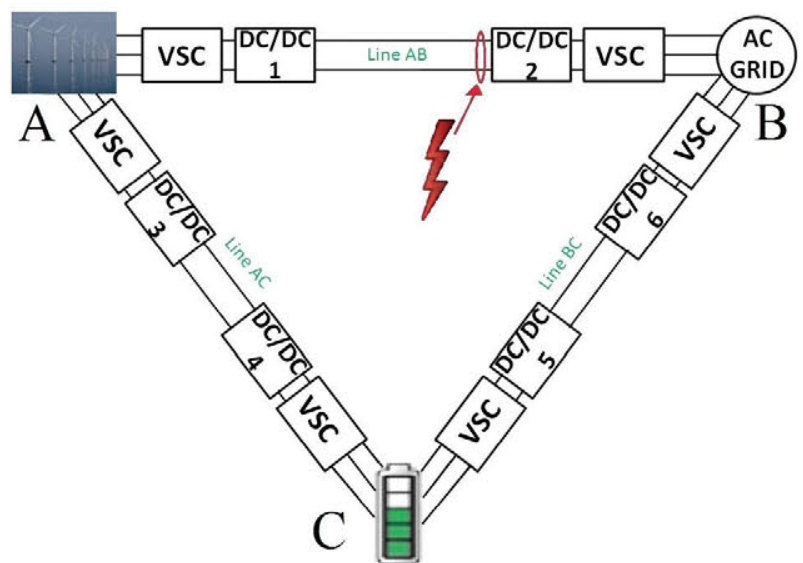

Figure 6: Short-circuit in the multi-terminal HVDC system.
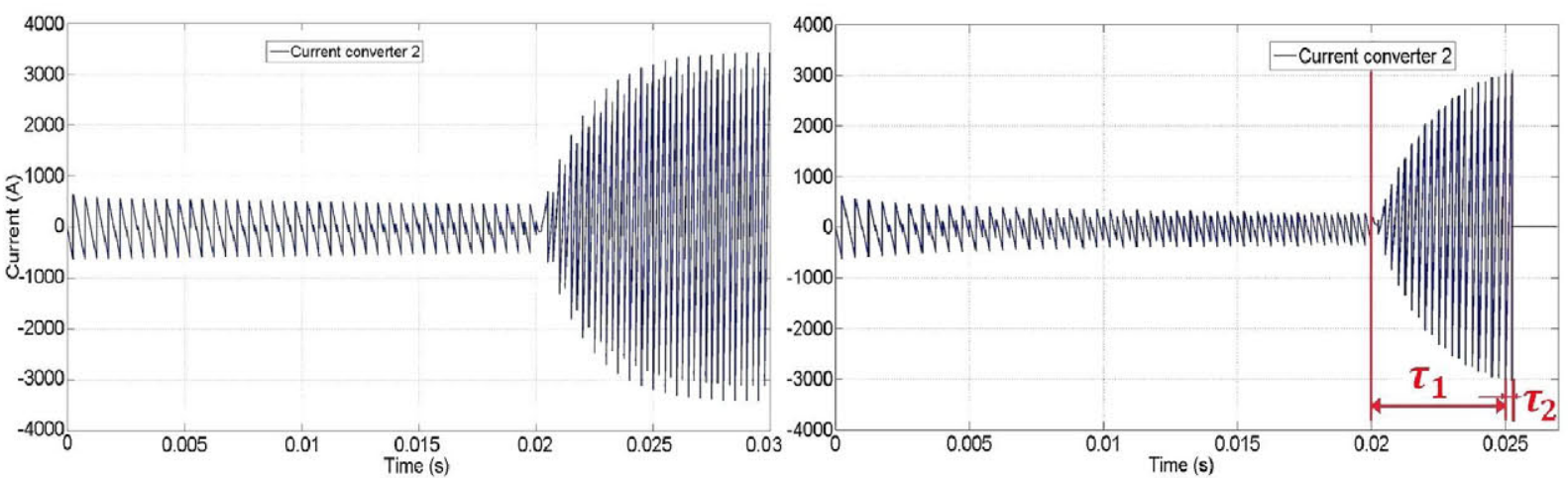

Figure 7: Multi-terminal HVDC system a) without DC circuit breakers b) with DC circuit breakers.

\subsection{Simulations for a single converter.}

As the figure 8 shows, the short-circuit practically has not influence in the behavior of the converters which are in other lines, because the VSC converters and the internal transformer of DC/DC converters mitigate the fault, so it seems sensible to study the short circuit more deeply in the line where it occurs. In this point, it must be mentioned that from the point of view of the DC/DC converter, the worst case is when the short-circuit appears in the other side of the line, because in this case is when more energy exits in the system, and more difficult is its dissipation, due to the inductance intrinsic nature of the line. Therefore we will study the behavior of a single converter as shows the figure 9, and we will assume that it is controlled as current source. The main idea of this section is that as the converter is controlled in current mode, and therefore we have the possibility of control the current, then we could drive gradually it and thus dissipate the fault in a more optimal way. This study was carry out using the software SIMetrix/SIMPLIS. The values of this figure 9 are in concordance with the table II, so the length of line is $160 \mathrm{Km}$, and consequently the values are: $R_{A B}=1.936 \Omega, L_{A B}=19.36 \mathrm{H}$ and $C_{A}=C_{B}=320 \mu \mathrm{F}$.

In this point, it is clear that the converter has two possible behaviors. The first one is when it is injecting power to the system, and the second one is when it is absorbing power. Both event will be discus separately.

\subsubsection{Injecting $1 \mathrm{kA}$}

When the converter is producing power and a short-circuit fault occurs, if $I_{r e f}$ (the current converter reference) is set to 0 immediately, the current stored in the inductor flows through the diodes of the switches and dissipates in $40 s$, as shown figure 10. Note that over-voltage does not appears in voltage $V_{A}$, and this is because they exist diodes in the converter (it must to size them correctly, in a way that they could support that current).

\subsubsection{Absorbing $0.5 \mathrm{kA}$}

This is the worst case because the diodes are not conducting due to the direction of the current, and therefore any current passes through them, and it passes through the capacitors. So if a short-circuit fault occurs, and if $I_{r e f}$ is set to 0 immediately, the current stored in the inductor can only flow through the capacitor $C_{A}$ and rings causing an over-voltage in it (around $120 \mathrm{kV}$ ) as shows figure 11. 

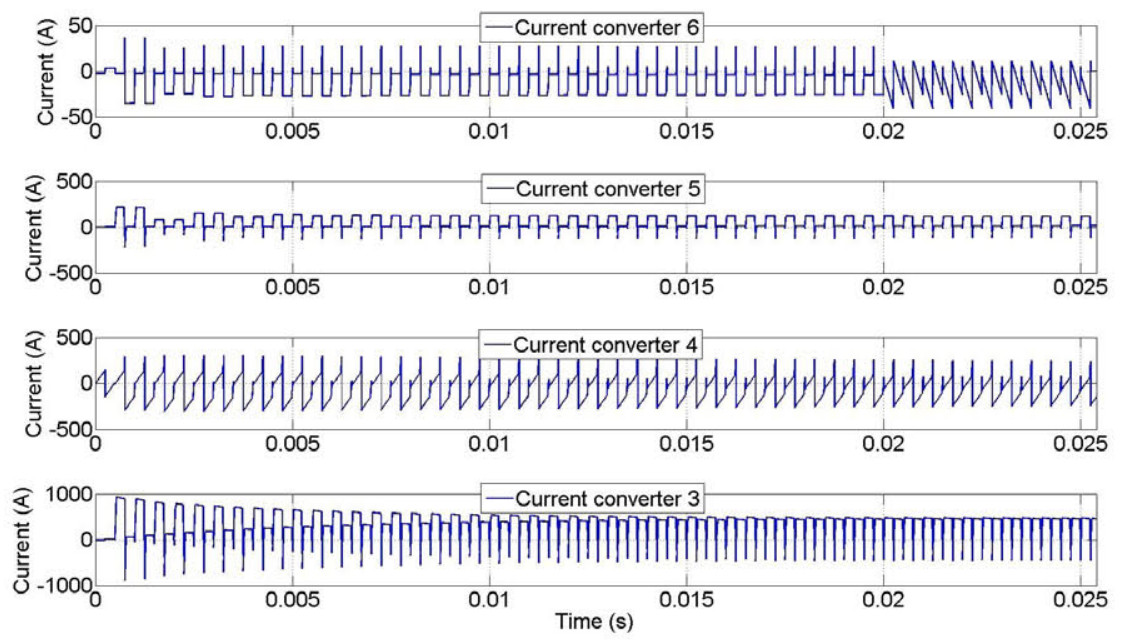

Figure 8: Current in the other converters.

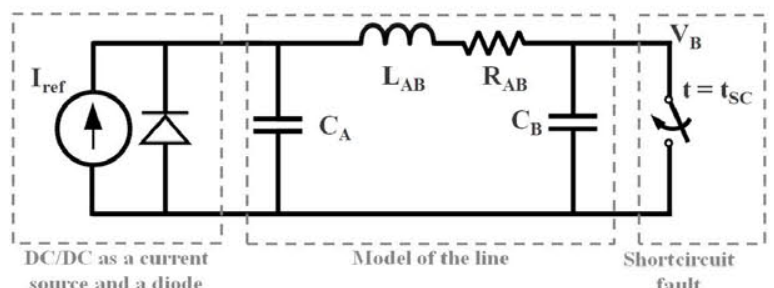

Figure 9: Line short-circuit model.
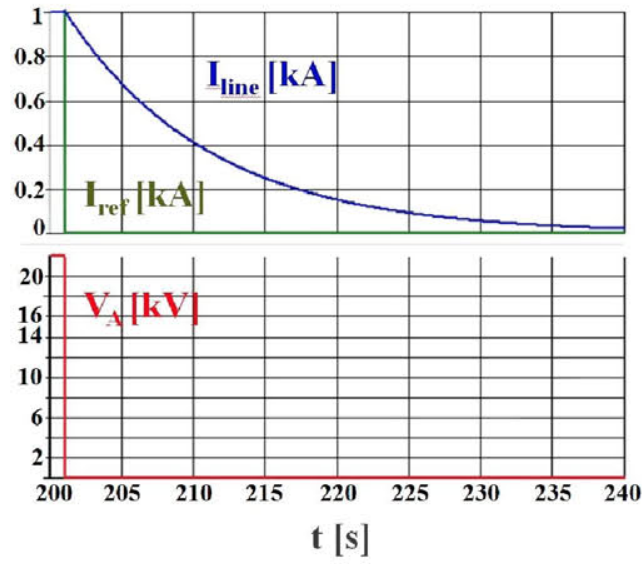

Figure 10: Current line and voltage at node $\mathrm{A}$ in injecting mode.

Hence in this mode, it is more convenient to apply a soft reference, and as we know the current line dynamic (in the worst case), we could apply a reference with this dynamic as shows the figure 12 . It is clear that when the converter is consuming power and a short-circuit fault occurs, if $I_{r e f}$ is reduced to 0 with a slow slew rate, the voltage in $C_{A}$ does not ring. Also we can observe that the power is also dissipated in $40 \mathrm{~s}$. In the right side of the figure 12 a zoom of the first instants of the short-circuit is shown. We observe as the voltage in $C_{A}$ discharges automatically in approx $1 \mathrm{~ms}$. This is because, just after the short-circuit occurs as $V_{A}>V_{B}=0$, and $I_{\text {line }}$ increases by taking current from $C_{A}$, discharging it.

\section{Conclusions}

This paper presents the modeling and control of a DC/DC bidirectional (DAB) for power applications in MT-HVDC grids. The robustness of the control under disturbances have been checked. Also the use of the DC/DC converter as a tool to regulate the power flow have been showed. The employ of the converter as a DC circuit-breaker have been proposed too. It is a new concept which can get that 

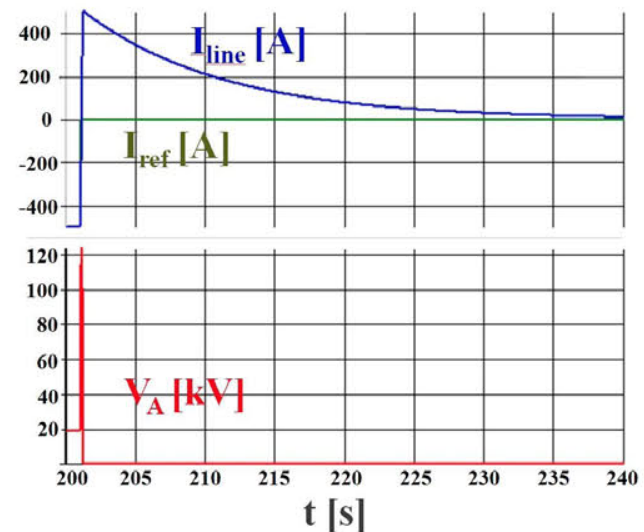

Figure 11: Current line and voltage at node $\mathrm{A}$ in demanding mode with over-voltage.
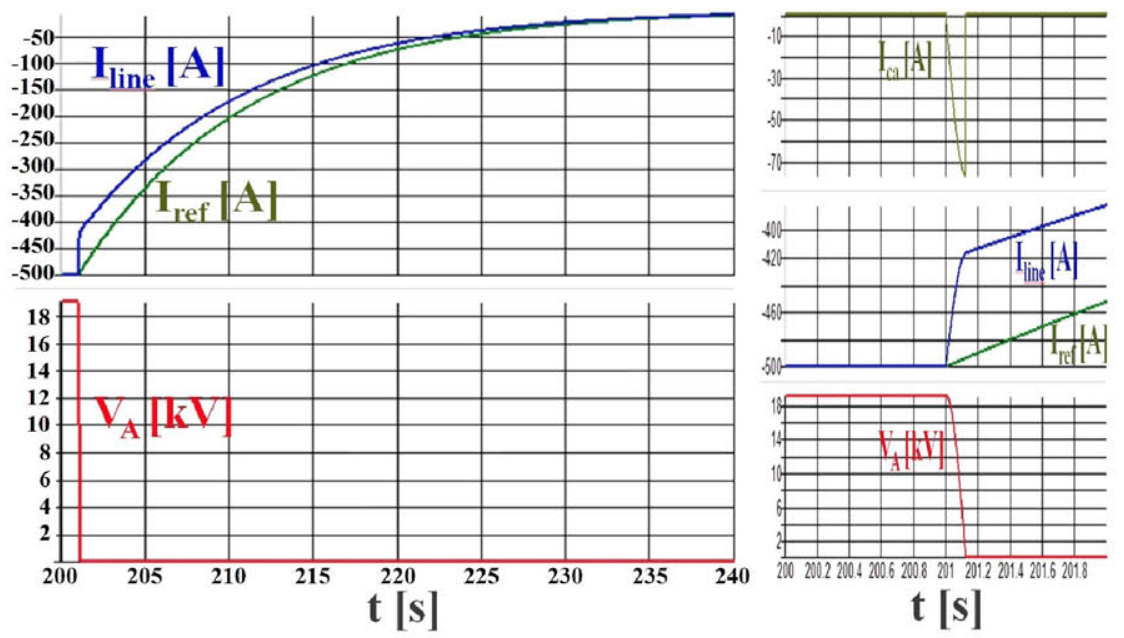

Figure 12: Current line and voltage at node $\mathrm{A}$ in demanding mode without over-voltage.

MT-HVDC networks will be more safety and it could be capital for the implementation of MT-HVDC networks. Finally, a new control current strategy under fault behavior is explained. Thanks this strategy, the converter suffers less when a short-circuit appears and the energy of it is softly dissipated. The proposed controller had a satisfactory performance in all of the simulations, and thanks to it, several systems could be integrated into a huge network in a safe way by means of plug \& play philosophy.

For future work, it could be interesting to study the transformer and its behavior during the short circuit.

\section{References}

[1] J. Arrillaga, Y. Liu, and N. Watson, Flexible Power Transmission. The HVDC Options. John Wiley \& Sons Ltd, 2007.

[2] G. Asplund, "Ultra high voltaje trasmission," ABB review, February 2007.

[3] J. Kreuse, "The future is now," ABB review, March 2008.

[4] S. Johansson, G. Asplund, E.Jansson, and R. Rudervall, "Power system stability. benefits with vschvdc transmission systems," CIGRE, 2007.

[5] G.Ortiz, J. Biela, and J. Kolar, "Optimized design of medium frequency transformers with high isolation requirements," 36th Conference on IEEE Industrial Electronics Society, November 2010.

[6] D. Aggeler, J. Biela, and J. Kolar, "Solid-state transformer based on sic jfet for future energy distribution systems," ETH Zurich, Power Electronic Systems Laboratory., 2009.

[7] M. Jiménez, A. Benchaib, P. Alou, and G. Damm, "Dc transformer for dc/dc connection in hvdc network," 15th European Conference on Power Electronics and Applications, September 2013. 
[8] C. Meyer, "Circuit breaker concepts for future high-power dc-applications," Industry Applications Conference. Fourtieth IAS Annual Meeting, vol. 2, pp. 860-866, Octobre 2005.

[9] C. Greiner, T. Langeland, J. Solvik, and O. A.Rui, "Availability evaluation of multi-terminal dc networks with dc circuit breakers," PowerTech, 2011 IEEE Trondheim, pp. 1-8, June 2011.

[10] J. Biela, D. Aggeler, D. Bortis, and J. W. Kolar, "5kv/200ns pulsed power switch based on a sic-jfet super cascode," IEEE Power Modulators and High Voltage Conference, pp. 358-361, May 2008.

[11] P. Friedrichs, H. Mitlehner, R. Schorner, K. Donhke, R. Elpelt, and D. Stephani, "Stacked high voltage switch based on sic vjfets," ISPSD Cambridge, April.

[12] R. Singhi, "Ultra high voltage sic bipolar devices for reduced power electronics complexity," GeneSiC Semiconductor Inc, February.

[13] J. Palmour, "High voltage silicon carbide power devices," ARPA-E Power Technologies Workshop, CREE Inc, February.

[14] A. Isidori, "Nonlinear control systems," Springer Verlag, 1995.

[15] H. K. Khalil, “Nonlinear systems,” Prentice Hall, 2002.

[16] ABB, "Abb circuit-breakers for direct current applications," ABB Review, September.

[17] G. Anderson, P. Kundur, and V. V. et al.

[18] ABB, "Hvdc light (R) cables. submarine and land power cables," ABB review, 2006.

[19] T. Tanaka, K. Kunii, T. Nakatsuka, K. Iionuma, H. Miyate, and T. Takahashi, "High performance hvdc polymer cable," 2000. 